\title{
A MATHEMATICAL MODEL FOR FOREST FIRES BLOWUP
}

\section{DOMINGOS XAVIER VIEGAS}

\author{
ADAI, Departamento de Engenharia Mecânica, Polo II da \\ Universidade de Coimbra, Coimbra, Portugal
}

\begin{abstract}
The very quick fire spread that occurs in some forest fires has been the cause of many fatalities in the past among fire fighters throughout the world. A theoretical model describing the convective interaction between the fire front and the surrounding air is proposed to explain the blowup phenomenon that is observed in nature. This model is based on a set of laboratory experiments of fire blowup in canyons that was used to validate it. The model predicts quite well the general fire behavior observed during two fatal accidents that occurred in the United States and one in Portugal.
\end{abstract}

Keywords: forest fires, fire dynamics, fire blowup, fire behavior, fireatmosphere coupling, fire-atmosphere interaction, fire eruption

Received 13 November 2003; accepted 18 May 2004.

The author wishes to thank to his colleagues Luis Pita and Luis Ribeiro for their help in the performance of the laboratory experiments and in the analysis of real cases from which results were used here. The experimental program in the laboratory was performed with the help of Mr. Nuno Luis, Mr. A. Cardoso, and Mr. P. Palheiro. Their support is gratefully acknowledged. The author is also indebted to his colleagues Dr. A. R. Figueiredo and Dr. L. A. Oliveira for their critical comments and corrections to this article. Support given by Comandante J. Mamede from the Fire Brigade of Freixo de Espada-à-Cinta during the investigation of Freixo accident is acknowledged. The availability of meteorological data for the same case by Quantific Company is also gratefully acknowledged. The present research is included in the program of Projects Winslope (Contract POCTI/34128/EME/2000) and SPREAD (Contract EVG1-CT2001-00043) supported respectively by Fundação para a Ciência e Tecnologia and by the European Commission under the Program Environment. This support is also gratefully acknowledged.

Address correspondence to Xavier.viegas@dem.uc.pt 


\section{INTRODUCTION}

It is reported in the literature (cf. Brown and Davis, 1973; Chandler et al., 1983; Pyne, 1984; Pyne et al., 1996) that on many occasions forest fires behave in a surprising way, changing suddenly from moderate behavior characterized by a relatively low rate of spread to an explosive propagation with a much faster velocity and heat release. In some instances, such behavior has caught by surprise and even killed experienced fire fighters, leaving them with no time or place to escape. This phenomenon is known in the literature as a fire blowup or flare-up and there is not a consistent justification for this behavior in the scientific literature. In particular, fires spreading in steep slopes, namely in ridges or canyons, are associated with such blowups that have caused many fatalities in the past. The Mann Gulch fire, described by Rothermel (1993), occurred in 1949 and caused 13 fatalities; the South Canyon fire of 1994, analyzed by Butler et al. (1998), had 14 fatalities; and the Thirtymile fire of 2001, described by Furnish et al. (2001), had four fatalities, all of which occurred in the United States. These are examples that have not been explained by science to this day. Another case, which occurred in Freixo, Portugal in the summer of 2003 and was investigated by the author (cf. Viegas, 2004a), had two fatalities; it is also an example of a blowup and will be used to test the present model.

When there is a canopy layer above the surface vegetation, fire may spread as a surface or as a crown fire. The latter is more complex and less studied. Although blowups are easily associated to crown fires, we shall assume in this paper that the fire is spreading only in the surface layer.

In this paper the author shows that the blowup is a result of feedback between the fire and the atmosphere that may occur naturally in steep terrain without the need of any special atmospheric conditions to justify its occurrence.

A theoretical model that takes into account the feedback mechanism of the convection induced by the fire is proposed. The model is validated using results from laboratory experiments and then applied to describe the blowup phenomenon that occurred in three fire-related accidents.

\section{THEORETICAL MODEL}

\section{Problem Formulation}

A forest fire spreads with a rate of spread (ROS) $R$ that is the result of a balance between the energy released at the fire front and the energy that is 
necessary to ignite the fuel adjacent to the fire. Its value is determined basically by fuel-bed properties, terrain slope, and wind flow in the vicinity of the fire in addition to the convective flow induced by the fire itself. Fires spreading on a slope or with favorable wind will form a head with a relatively high ROS in relation to other parts of the fire perimeter. Our attention is focused on the head fire ROS. We assume that all fuel-bed and terrain properties are homogeneous and uniform and that all time-dependent properties such as ambient wind velocity and direction remain constant during fire spread. For simplicity, it is assumed that vectors such as flow velocity and ROS are parallel to a common direction and, therefore, they can be represented by a single component and treated in the equations as scalars.

\section{Mathematical Model}

If we consider a reference value $U$ of the convective flow velocity near the fire front, with all other parameters remaining constant, the ROS for a given fuel bed will depend only on $U$ :

$R=f(U)$

The choice of the characteristic wind velocity of the flow, $U$, in the vicinity of the fire front is a matter of debate. It is well known that when the approaching flow is of the boundary-layer type, wind velocity varies from zero at the ground to a practically constant value in the limit of the boundary layer. It is usual to refer to the wind velocity at a standard height of $10 \mathrm{~m}$ above the ground, which is done in meteorology. Because this height may be excessive for the characterization of the flow of relatively small flames, Rothermel (1972) proposed to consider the wind velocity at the midflame height as a reference flow velocity. On the other hand, Viegas and Neto (1992) propose the use of the friction velocity $u_{\tau}$ for this purpose, given its purpose of characterizing the shear stress produced by the flow on the ground that dominates the momentum and energy transfer near the surface. In this work, this point is not discussed further and it is assumed that some characteristic value of the flow velocity, $U$, can be defined to describe the interaction between the atmospheric flow and the flaming fire front.

Using an analogy between slope and wind effects on fire spread (cf. Morandini et al., 2002; Nelson, 2002; Rothermel, 1983), we can consider that the effect of a slope on the rate of spread is equivalent to a given 
value of the flow velocity on a horizontal fuel bed. According to this analogy, both effects are equivalent and an effective wind is considered as a surrogate of slope effect. This is an approximation, but its adoption is convenient to deal with slope and wind effects using the same formalism for both cases, describing both with a single parameter, $U$.

In this paper we consider mainly fire propagation in a slope, but the present considerations are also applicable to a fire front under permanent and uniform wind conditions. As was said earlier, we assume that a reference flow velocity $U$ can be defined and that this velocity is constant and parallel to the ROS vector.

Many fire simulation models do not consider the effect of the fire on the atmospheric flow and all the computations are made using the isothermal flow that existed over the vegetation in the absence of the fire. This hypothesis can be valid for fires spreading downslope or against wind, but for high-intensity fires the interaction between the ambient flow and the reactive fuel bed will modify the flow in the vicinity of the fire front and modify the rate of spread, as was shown by Viegas (2004b).

If we consider that the characteristic velocity of the isothermal flow is $U_{\mathrm{a}}$ - that is, uniform and constant in the entire domain of calculationthen the instantaneous characteristic velocity of the flow in the presence of the fire will be different from $U_{\mathrm{a}}$. We can state this mathematical inequality with the following equation:

$U=U_{\mathrm{a}}+U_{\mathrm{f}}$

In this equation, $U_{\mathrm{f}}$ is the equivalent of some characteristic velocity induced by the presence of the fire that, when added to the initial ambient flow $U_{\mathrm{a}}$, gives the characteristic flow velocity $U$. This equation does not mean that effects of both ambient wind and induced convective flow are additive: it only states that the characteristic flow velocity in the presence of the flame is not the same as that in the case of isothermal flow. In the general case, this induced flow velocity will be a function of time and we may write that

$U(t)=U_{\mathrm{a}}+\int_{i}^{t} \frac{\mathrm{d} U_{\mathrm{f}}}{\mathrm{d} t} \mathrm{~d} t$

where the only factor that can change ROS is the convective flow velocity $U$. Any change to $U$ can only come from the heat released at the fire front, because $U_{\mathrm{a}}$ is constant:

$\mathrm{d} U=\mathrm{d} U_{\mathrm{a}}+\mathrm{d} U_{\mathrm{f}}=\mathrm{d} U_{\mathrm{f}}$ 
The change in the wind velocity, $\mathrm{dU}_{\mathrm{f}}$, induced by fire during $\mathrm{d} t$ will depend on the heat released by the fire front. It is well known that for a given fuel bed the amount of heat released by unit of time per unit of fire front length - the so-called Byram fire line intensity - is proportional to the ROS. This means that the convective flow that is induced by this energy release will also keep some relationship to the ROS of the fire front. We assume, therefore, that this heat release is related univocally to the ROS and, consequently, for a given fuel bed it can be expressed as a function of the ROS and we can write

$\mathrm{d} U_{\mathrm{f}}=g(R) \mathrm{d} t$

Differentiating Eq. (1), we have the change of rate of spread that is produced by the change of flow velocity, $\mathrm{d} U$, during $\mathrm{d} t$ :

$\mathrm{d} R=\frac{\mathrm{d} f}{\mathrm{~d} U} \mathrm{~d} U=\frac{\mathrm{d} f}{\mathrm{~d} U} g \mathrm{~d} t=\frac{\mathrm{d} R}{\mathrm{~d} t} \mathrm{~d} t$

Integrating Eq. (6) between $t_{i}$ and $t$, we can obtain the rate of spread variation with time:

$R-R_{i}=\int_{t_{i}}^{t} \frac{\mathrm{d} R}{\mathrm{~d} t} \mathrm{~d} t$

where $R_{i}$ is the initial value of the rate of spread for $t=t_{i}$.

The present model is based on the assumption that functions $f$ and $g$ both exist, are well defined, and can be determined. This point is discussed in the following section. At present we have to keep in mind that in the general case these functions will depend on fuel-bed properties.

\section{Nondimensional Formulation}

It is usual in engineering practice to express the mathematical equations that describe a given physical problem in nondimensional form to render them independent of the particular scale or other properties of given realizations of the process described by the equations. To derive a nondimensional formulation of the problem, we need to define some characteristic parameters that can be used as reference scales. The choice of these parameters has some degrees of freedom but it must be made 
with certain criteria to ensure that all relevant phenomena are considered in the analysis.

The process of deriving nondimensional forms of the equations has the advantage of putting in evidence the relevant parameters that govern the problem.

The nondimensional form of functions $f, g$, and $R(t)$ can then be applied to different practical conditions, namely for different fuel-bed types. We should expect that for a given terrain geometry the development of a blowup will be different in the case of litter, herbaceous, or shrub vegetation, for example. In spite of this, provided that adequate reference parameters are chosen, the same general blowup equation is applicable for all cases, as we shall see.

In the present case, the choice of reference scale factors falls on the basic rate of spread, $R_{\mathrm{o}}$, a reference wind velocity $U_{\mathrm{o}}$ and a characteristic timescale $t_{\mathrm{o}}$.

The basic rate of spread, $R_{\mathrm{o}}$, is the ROS value for the same fuel bed in the absence of wind and slope; its value can be easily measured in practice. It depends on the fuel-bed properties, namely on the moisture content of the fuel bed's very fine particles. Although $R_{\mathrm{o}}$ is a kinematic parameter, it is chosen here for its role in characterizing the energy release and heat transfer processes in a given fuel bed. It is well known (cf. Albini, 1985; Rothermel, 1972) that by solving the energy release and heat transfer equations the rate of spread is given as a solution of the temperature field problem.

The reference wind velocity $U_{\mathrm{o}}$ can be defined as the value that is required to produce a given increase in the ROS for that fuel. For example, we could consider $U_{\mathrm{o}}$ equal to the value of $U$ that makes $f=5$. In principle, this will be a specific property of a given fuel bed. It is known (cf. Rothermel, 1972; Viegas and Neto, 1992) that the reaction of the fuel bed to wind in terms of ROS increase depends very much on its porosity. Heavy fuels like forest litter and residues require much higher values of the wind speed $U_{\mathrm{o}}$ to produce a given increase in the ROS, whereas fine fuels like herbaceous vegetation require a much lower value to produce the same effect. In this study because we do not have enough data to estimate $U_{\mathrm{o}}$ for all the situations that are analyzed we shall set $U_{\mathrm{o}}=1 \mathrm{~m} / \mathrm{s}$ for simplicity.

The characteristic timescale $t_{\mathrm{o}}$ is a measure of the inertia of the fire front in that fuel; it can be assimilated to some residence time of the flame for the fuel particles that enter in the composition of the fuel that is also 
a specific property of the fuel bed. It can be measured from thermocouple data by the duration of the temperature trace inside the fuel bed above a certain threshold of, say, $400^{\circ} \mathrm{C}$. Again, heavy like, slash or litter, fuels with relatively large particles and high values of fuel load (amount of fuel per unit area of the forest) will have larger values of $t_{\mathrm{o}}$ compared to light fuels like herbaceous vegetation.

We shall express fire spread equations in terms of the following nondimensional variables:

$R^{\prime}=\frac{R}{R_{\mathrm{o}}}$

$U^{\prime}=\frac{U}{U_{\mathrm{o}}}$

$t^{\prime}=\frac{t}{t_{\mathrm{o}}}$

\section{Semi-empirical Solution}

In principle, the functions $f$ and $g, R_{\mathrm{o}}$, and all the other parameters that are required by the present model could be obtained from theoretical considerations by solving the adequate mathematical equations describing the physical and chemical processes that take place in the fire front and using the adequate boundary conditions. At present, physical models are not developed to a stage of providing these properties of fire spread in the general case. Therefore, we shall use empirical formulations and results to close the problem and to check the validity of the present model.

Function $g$ can also be determined directly from laboratory or field experiments using the appropriate flow velocity measuring sensors. In this study, its form shall be determined indirectly from laboratory experiments.

The basic ROS, $R_{\mathrm{o}}$, and the other reference parameters shall be determined from experimental results, either from direct measurements or from calculations as shall be explained following.

Among the many formulations for $f$ that can be found in the literature, we shall adopt one that is commonly used (cf. Rothermel, 
1972, 1983; Viegas, 2002a), which uses a power law function to describe the dependence of the ROS on wind velocity:

$R^{\prime}=1+a_{1} U^{b_{1}}$

As will be explained later, this function was obtained by the author in laboratory experiments using a combustion tunnel with controlled fuel-bed properties and wind flow.

For simplicity, we shall adopt for the function $g$ a power law form as well, given by the following equation:

$\mathrm{d} U^{\prime}=a_{2} R^{\prime b_{2}} \mathrm{~d} t$

In the preceding equations, coefficients $a_{1}$ and $a_{2}$ have physical dimensions and are determined empirically. The following pair of nondimensional parameters can be defined:

$a_{1}^{\prime}=a_{1} U_{\mathrm{o}}^{b_{1}}$

$a_{2}^{\prime}=a_{2} t_{\mathrm{o}}$

Using these definitions, it is easy to check that Eqs. (11) and (12) can be expressed in the following nondimensional forms:

$R^{\prime}=f^{\prime}\left(U^{\prime}\right)=1+a_{1}^{\prime} U^{\prime b_{1}}$

and

$\mathrm{d} U^{\prime}=g^{\prime}\left(R^{\prime}\right) \mathrm{d} t^{\prime}=a_{2}^{\prime} R^{\prime b_{2}} \mathrm{~d} t^{\prime}$

Solving Eq. (15) for $U^{\prime}$, using Eq. (16), and introducing the result in Eq. (6), it is easy to find that

$\frac{\mathrm{d} R^{\prime}}{\mathrm{d} t^{\prime}}=a_{1}^{\prime} \frac{1}{b_{1}} b_{1} a_{2}^{\prime}\left(R^{\prime}-1\right)^{1-\frac{1}{b_{1}}} R^{\prime b_{2}}$

This equation shows that for $R^{\prime}=1$ there is no acceleration of the fire front and the ROS remains constant. The acceleration value is very low if $R^{\prime}$ is very close to one, but it increases monotonically with $R^{\prime}$. This equation also shows that whenever $R^{\prime} \neq 1$ the ROS of the fire will 
change with time, even if all the other boundary conditions remain unchanged, as assumed in the present formulation.

A particular solution of this equation is obtained by making $b_{1}=b_{2}=1$, thus assuming that functions $f^{\prime}$ and $g^{\prime}$ are linear in $U^{\prime}$ and $R^{\prime}$, respectively. This approach can only be valid in a limited range of those variables. This case is quite interesting because it leads to an explicit solution of Eq. (17) that corresponds to an exponential growth of the ROS with time. This solution is found for a fire front propagating up slope in a vertical wall of solid combustible material (cf. Drysdale, 1992), which has some analogy with the present case of a porous solid fuel bed in a steep slope.

In this preliminary study, the author intends to demonstrate the relevance of the present model to predict fire blowup. Because there are not sufficient data to determine the reference parameters $t_{\mathrm{o}}, R_{\mathrm{o}}$, and $U_{\mathrm{o}}$ in the general case, we shall use a partial nondimensional form of the equations to apply them to practical cases. In the absence of specific data, we shall set $U_{\mathrm{o}}=1 \mathrm{~m} / \mathrm{s}$ in the present study.

\section{EXPERIMENTAL RESULTS}

Laboratory experiments were carried out by the author and his collaborators (Viegas et al., 2002b) in the combustion tunnel (CT) of the Forest Fire Laboratory of the University of Coimbra using a fuel bed of dead needles of Pinus pinaster with a fuel load of $1 \mathrm{~kg} / \mathrm{m}^{2}$ and a packing ratio (ratio of solid volume to the total volume of the fuel bed) of 0.003 . The CT has a horizontal platform of $3 \times 8 \mathrm{~m}^{2}$ where the fuel bed is prepared; it has two vertical walls $1.5 \mathrm{~m}$ high and is open on the top; wind flow is produced by two axial fans of variable rotational speed: and flow straighteners are introduced between the fan ducts and the working section of the tunnel. Fires with linear ignitions for constant values of the wind velocity were studied in the range $0<U_{\mathrm{a}}<5 \mathrm{~m} / \mathrm{s}$. The ROS was measured along the test bed by using visual techniques developed by the author and his co-workers. As a result, the following values were obtained for $a_{1}=1.10$ (SI units) and $b_{1}=2.02$ for Eq. (11). The basic ROS for this fuel bed was in the range $0.22<R_{\mathrm{O}}<0.34 \mathrm{~cm} / \mathrm{s}$. The residence time $t_{\mathrm{o}}$ of the flame at a given point of the fuel bed was evaluated using a thermocouple, and the average value found for the pine needles was $t_{\mathrm{o}}=80 \mathrm{~s}$.

A series of tests was carried out in a device that has the configuration of a canyon. This device is shown in Figure 1; it has two rectangular plates that form a dihedral with an angle $\gamma$ and their intersection line has 


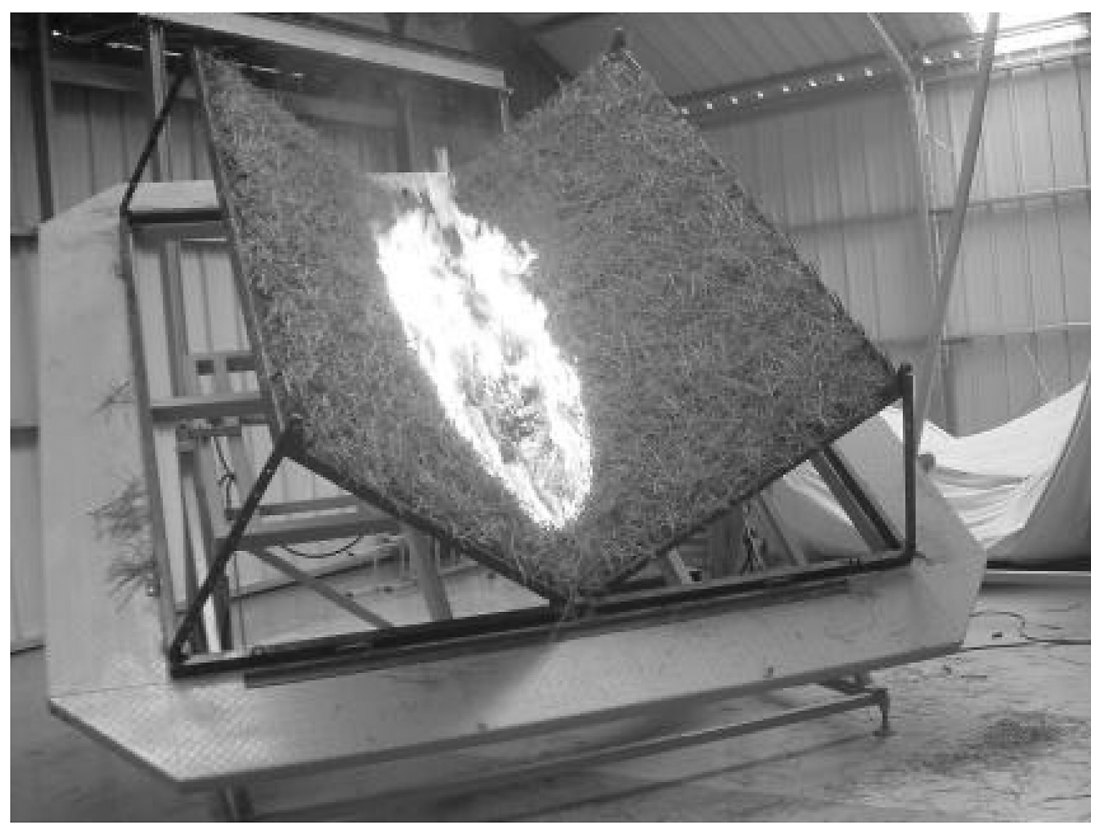

Figure 1. Experimental setup in the Forest Fire Laboratory of the University of Coimbra for the study of fire spread in canyons and for the observation and analysis of blowup phenomena.

an inclination $\alpha$ in relation to the horizontal ground (cf. Figure 2). The dimensions of each face are $2.9 \times 1.45 \mathrm{~m}^{2}$. By changing the values of $\alpha$ and $\gamma$ it is possible to replicate typical canyon configurations in reality.

The pairs of values of $\alpha$ and $\gamma$ used in the experimental program are given in Table 1 with the corresponding designation for each test. The same fuel bed was used in all tests and fire was ignited at a single point in the intersection line of the two faces, $50 \mathrm{~cm}$ above the base of the canyon. In these experiments there was no superimposed wind and care was taken to avoid air draughts inside the laboratory hall. The evolution of the fire front was recorded using video- and infrared cameras and the ROS of the fire was evaluated from analyses of these images. Results reported here refer to the head fire spreading along the maximum slope gradient direction of the canyon faces.

As mentioned earlier, in the present study we did not measure the induced flow velocity in the vicinity of the fire front, and so we will determine the function $g^{\prime}$ empirically by fitting the present model to the 


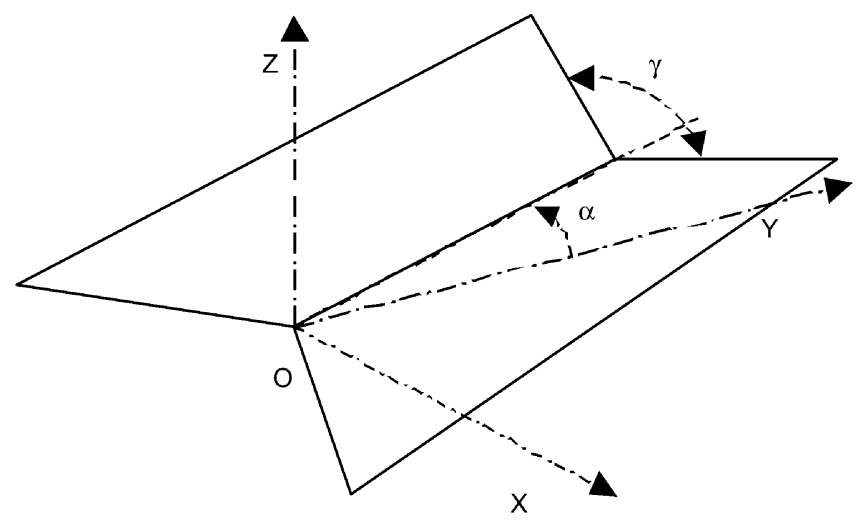

Figure 2. Schematic presentation of canyon configuration with definition of reference axis and characteristic angles.

results obtained in a set of laboratory experiments. From the 17 studied cases that are shown in Table 1, 9 were chosen to evaluate $a_{2}$ and $b_{2}$. The remaining eight cases were then used to test and validate the model. Later, a real-life case in which the flow velocity near the fire was actually measured shall be used to confirm the validity of this method.

To determine the parameters $a_{2}$ and $b_{2}$, we solve Eq. (17) to define the following function:

$Y=\frac{\mathrm{d} R^{\prime}}{\mathrm{d} t^{\prime}} \frac{\left(R^{\prime}-1\right)^{\frac{1}{b_{1}}-1}}{a_{1}^{\prime \frac{1}{b_{1}}} b_{1}}=a_{2}^{\prime} R^{\prime b_{2}}$

Table 1. Parameters of the laboratory tests with canyon-shaped terrain

\begin{tabular}{|c|c|c|c|c|c|}
\hline \multicolumn{3}{|c|}{ Test cases } & \multicolumn{3}{|c|}{ Validation cases } \\
\hline Ref. & $\alpha$ & $\gamma$ & Ref. & $\alpha$ & $\gamma$ \\
\hline 516 & $10^{\circ}$ & $158^{\circ}$ & 511 & $10^{\circ}$ & $140^{\circ}$ \\
\hline 512 & $20^{\circ}$ & $140^{\circ}$ & 517 & $20^{\circ}$ & $158^{\circ}$ \\
\hline 518 & $30^{\circ}$ & $158^{\circ}$ & 513 & $30^{\circ}$ & $140^{\circ}$ \\
\hline 514 & $40^{\circ}$ & $140^{\circ}$ & 518 & $40^{\circ}$ & $158^{\circ}$ \\
\hline 506 & $10^{\circ}$ & $114^{\circ}$ & 501 & $10^{\circ}$ & $100^{\circ}$ \\
\hline 502 & $20^{\circ}$ & $100^{\circ}$ & 507 & $20^{\circ}$ & $114^{\circ}$ \\
\hline 508 & $30^{\circ}$ & $114^{\circ}$ & 503 & $30^{\circ}$ & $100^{\circ}$ \\
\hline 531 & $40^{\circ}$ & $180^{\circ}$ & 509 & $40^{\circ}$ & $114^{\circ}$ \\
\hline 533 & $30^{\circ}$ & $180^{\circ}$ & & & \\
\hline
\end{tabular}




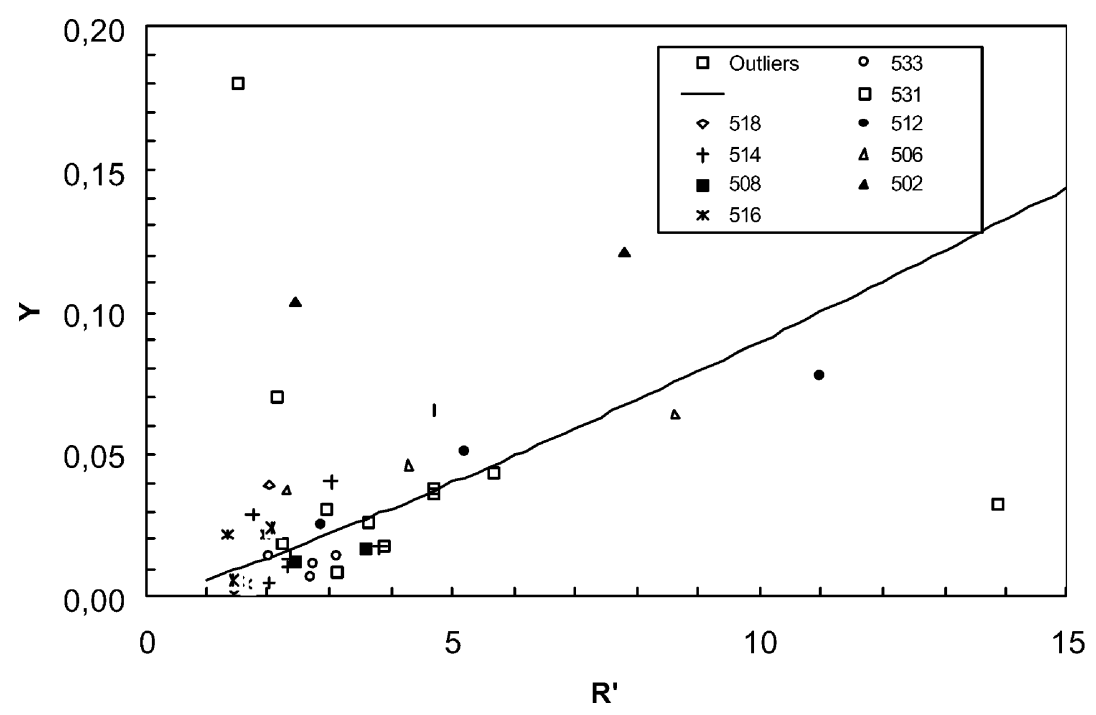

Figure 3. Experimental evaluation of parameters $a_{2}^{\prime}$ and $b_{2}$.

The values of function $Y$ can be computed for each test and the results are shown in Figure 3. A best fit of the power law function given by Eq. (18) with the experimental results was made using least-squares error. Two points were excluded from the analysis as outliers. The values obtained were, respectively, $a_{2}^{\prime}=0.0062$ and $b_{2}=1.16$ with a value of $r^{2}=0.396$.

Using these values and considering $R_{i}^{\prime}=1.1$, Eq. (15) was integrated yielding the result that is shown in Figure 4 as a solid line curve. As can be seen, the present model predicts the very sudden change on the ROS that is actually observed in the experiments, confirming that the blowup effect is derived exclusively from fire dynamics.

The results obtained in the eight remaining experimental cases were then used to validate the model. To fit those data, the value of $t_{i}$ was adjusted in each case to provide an overall best fit, because each test starts with a given value of $R_{i}^{\prime}$. The results are shown in the same figure for comparison. Quite good overall agreement between the model and the experimental data can be judged from this figure.

According to the present model the time history of the fire depends essentially on the fuel-bed properties and on the initial conditions $R_{i}^{\prime}$ that are dictated mainly by terrain configuration. 
In the application of this model, it is necessary that the boundary conditions remain the same during the period of analysis. This condition is more likely to be satisfied in fires spreading in a sufficiently long slope. For wind-driven fires, it is not so probable that wind velocity remains constant during the entire period until blowup occurs, but this may happen in some cases, at least for short periods. The solution given in this paper is not dependant on the particular forms that were adopted for $f^{\prime}$ and $g^{\prime}$. Tests made with other types of functions, like polynomials, or using different but realistic values of coefficients $a^{\prime}{ }_{1}, a^{\prime}{ }_{2}, b_{1}$, and $b_{2}$, led to results similar to the ones presented here.

\section{Real Cases}

Two accidents that are reported in the literature (Butler et al., 1998; Furnish et al., 2001), the South Canyon fire (SC) and the Thirtymile fire (TM), shall be used to demonstrate the practical validity of the present model. A third case that occurred in Portugal in August of 2003, which was investigated by the author, will also be analyzed.

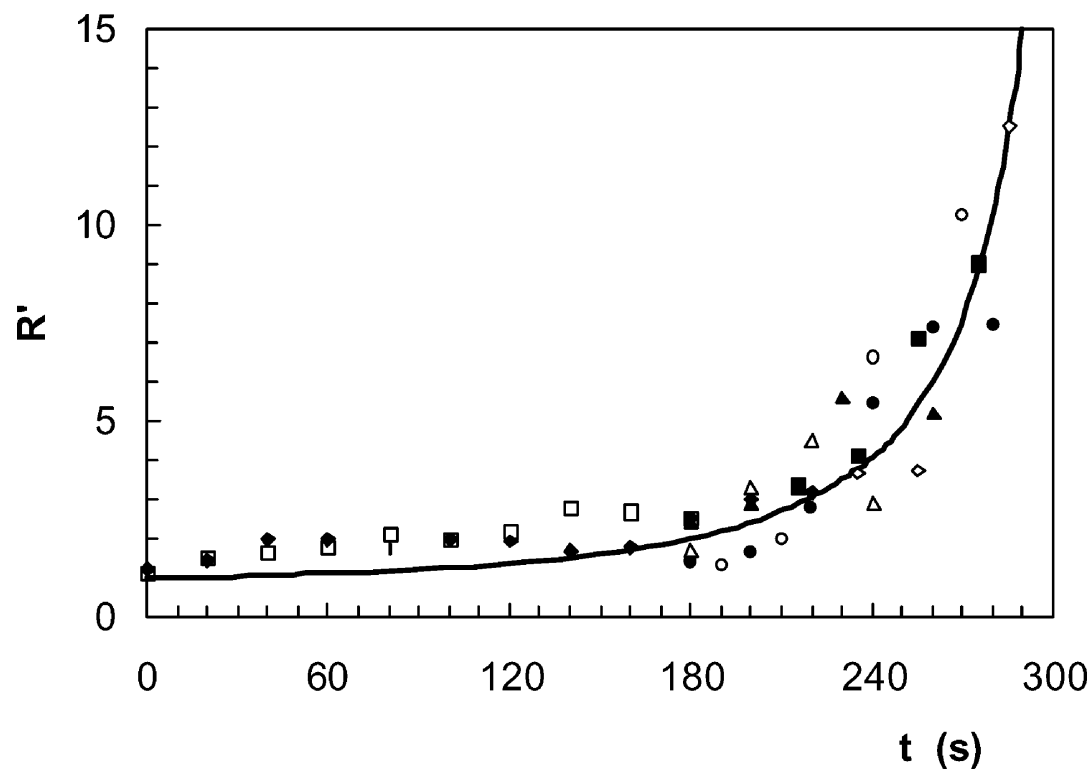

Figure 4. Comparison between present model (solid line) and experimental results for the validation cases of fire spread in a canyon. Symbols correspond to the referenced tests: 


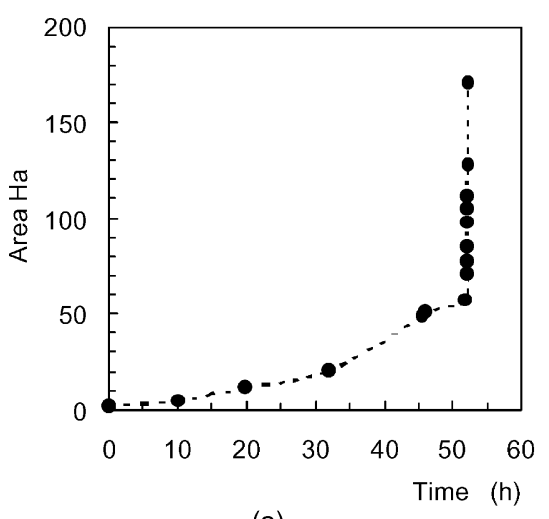

(a)

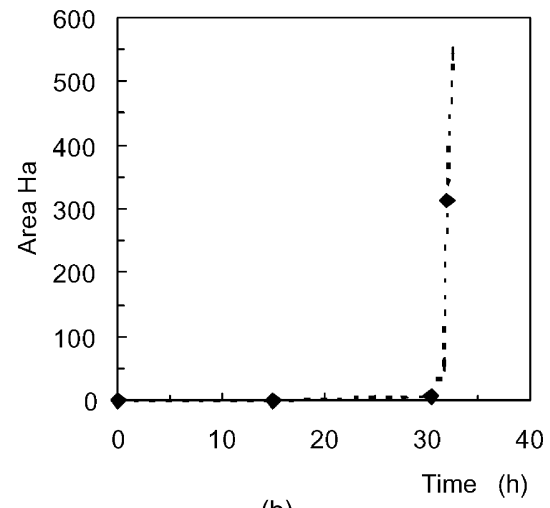

(b)

Figure 5. Area growth since fire origin for (a) South Canyon fire and (b) Thirtymile fire.

The history of the two cases that occurred in the United States is illustrated in Figure 5 with the change of area with time elapsed since fire ignition. As can be seen, the blowup effect is very evident in both cases. The fire burned relatively slowly for several hours or even days after ignition and in both cases suddenly spread very rapidly, burning in less than one hour a much greater area than it had done in the previous duration of the fire. In both cases, this happened when the fire reached steep slopes. Blowup started 46 and $30 \mathrm{~h}$ after fire start for SC and TM, respectively, as can be seen in Figure 5.

From both reports, it is possible to estimate ROS values during the relevant periods of the fires. Average values of the ROS in the period before blowup were evaluated and taken as $R_{\mathrm{O}}$ for each case as fire was spreading downslope for SC and on essentially flat and horizontal terrain for TM. The estimated values of $R_{\mathrm{o}}$ are given in Table 2 . The absolute

Table 2. Model parameters for laboratory experiments and for real cases

\begin{tabular}{lccccc}
\hline Description & Symbol & Units & Exper. & SC & TM \\
\hline $\begin{array}{l}\text { Time elapsed from fire origin } \\
\quad\end{array}$ & $t_{\mathrm{i}}$ & $\mathrm{h}$ & - & 46 & 30 \\
$\quad$ bo start of blowup & & & & & \\
Basic rate of spread & $R_{\mathrm{o}}$ & $\mathrm{m} / \mathrm{s}$ & $2.64 \times 10^{-3}$ & $1.66 \times 10^{-3}$ & $5.56 \times 10^{-3}$ \\
Initial nondimensional ROS & $R^{\prime}{ }_{\mathrm{i}}$ & - & $1.1-4$ & $2.5(100)$ & 1.2 \\
Coefficient defined in Eq. (13) & $a_{2}$ & $\mathrm{~s}^{-1}$ & $6.2 \times 10^{-3}$ & $4.5 \times 10^{-5}$ & $5.2 \times 10^{-5}$ \\
Residence time & $t_{\mathrm{o}}$ & $\mathrm{s}$ & 80 & $1.1 \times 10^{4}$ & $0.95 \times 10^{4}$ \\
\hline
\end{tabular}


values of $R$ are very close to the ones that are presented in the reports for both cases. The values of the initial ROS, $R_{i}^{\prime}$, when blowup started were also evaluated and they are given in the same table. The value that was considered in the simulation for the case of the SC fire is in parentheses.

To apply the present model to these two cases, it will be assumed that the wind effect on the ROS is given by the same function as for the laboratory case, having the same exponent $b_{2}$ in all cases. Because there is certainly a difference between the timescales characteristic of the laboratory fuel bed and that of the real forest, in both cases we shall assume that the coefficient $a_{2}$ changes from one case to another accounting for that difference. To estimate $a_{2}$ for the real fires we integrate Eq. (17) for the known value of $R_{i}^{\prime}$ and adjust $a_{2}$ until the ROS $R^{\prime}$ reaches an observed value for the corresponding value of $t$. Using $a_{2}$ equal to $4.5 \times 10^{-5}$ and $5.2 \times 10^{-5} \mathrm{~s}^{-1}$ for the SC and TM cases, respectively, the curves shown in Figure 3 were obtained. The corresponding values for $t_{\mathrm{o}}$ are, respectively, $11 \times 10^{3}$ and $9.5 \times 10^{3} \mathrm{~s}$ for the cases considered. Although the order of magnitude of $t_{\mathrm{o}}$ is similar to the values measured by the author for shrub vegetation (cf. Viegas et al., 2002b), the precise values may be different because we are not evaluating the exact value of $U_{\mathrm{o}}$ for each case and we assume that $U_{\mathrm{o}}=1 \mathrm{~m} / \mathrm{s}$ in all cases.

Comparison with the observed results shows that the present model predicts the trend in fire behaviur quite well, namely the very rapid increase of the ROS that is reported. Probably a better fit would be obtained with other sets of parameters $a_{1}, b_{1}$, and $b_{2}$, but at present there are no data to support preference of any other particular choice. The last three points presented in Figure $6 a$ do not follow the trend predicted by the model. Like the others, these points were obtained from the corresponding report, but they must correspond to a deceleration phase of the fire when it reached the top of the ridge and started to descend the opposite slope.

\section{The Case of Freixo}

During the summer of 2003, among the various fatal accidents that occurred in Portugal that were investigated by the author, there is one that occurred at Freixo de Espada-à-Cinta on August 5 (cf. Viegas, 2004a). For simplicity this case will be designated as Freixo. In this accident, two persons lost their life due to a sudden fire blowup on the wide slope in which the fire developed in the bank of the River Douro in the northeast of Portugal just inside the border between Portugal and Spain. A map of the 

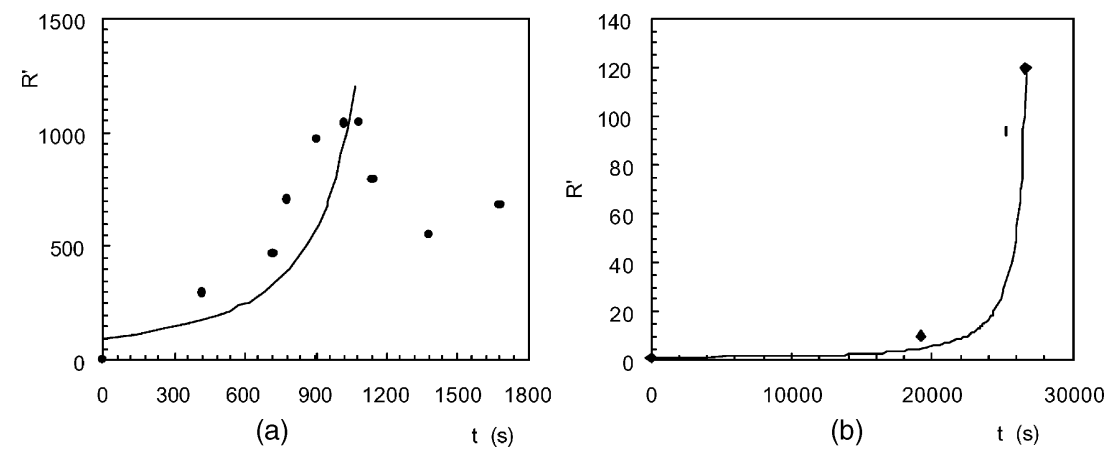

Figure 6. Variation of the rate of spread during blowup. Comparison between reported results and present model for $(a)$ South Canyon fire and $(b)$ Thirtymile fire.

area that is a partial reproduction of the $1 / 25,000$ maps produced by the Geographic Institute of the Portuguese Army is shown in Figure 7. The area of interest for the present study was covered by surface vegetation that was a mixture of herbaceous-type vegetation with shrubs and some agricultural fields. The origin of the fire that occurred at $14: 30 \mathrm{~h}$ is marked in the map as point $\mathrm{A}$. The fire fighters tried to maintain the fire in the lower

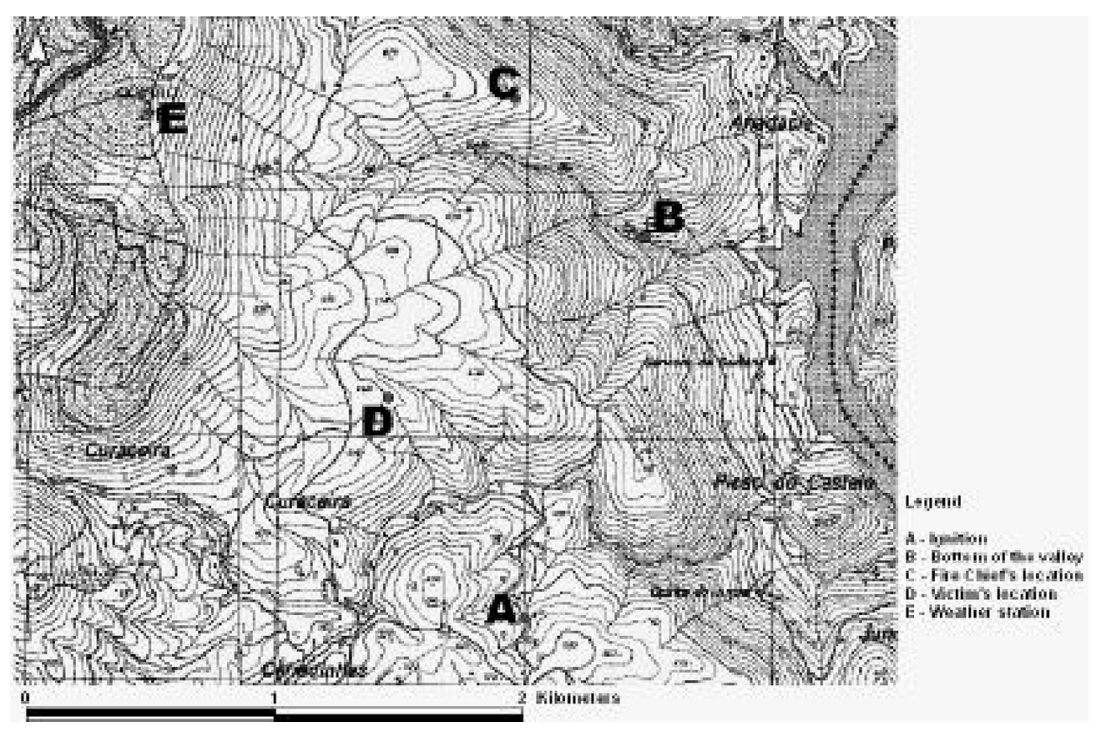

Figure 7. Topographic map of the area of the Freixo fire. North is indicated by the white arrow in the top-left corner of the figure. 
part of the slope and let it burn in the direction of the river bank. When it reached the point marked $\mathrm{B}$, the fire was practically controlled; only a small section of less than $50 \mathrm{~m}$ of fire line remained to be extinguished. At this stage, the fire boss, who was at point $\mathrm{C}$ with a machine that was creating a fire break, informed his superiors that the fire was under control. Then suddenly the fire started to spread very quickly up the slope of a canyon that exists above point B (cf. Figure 8) and blew up along the entire slope, reaching its top in a matter of minutes.

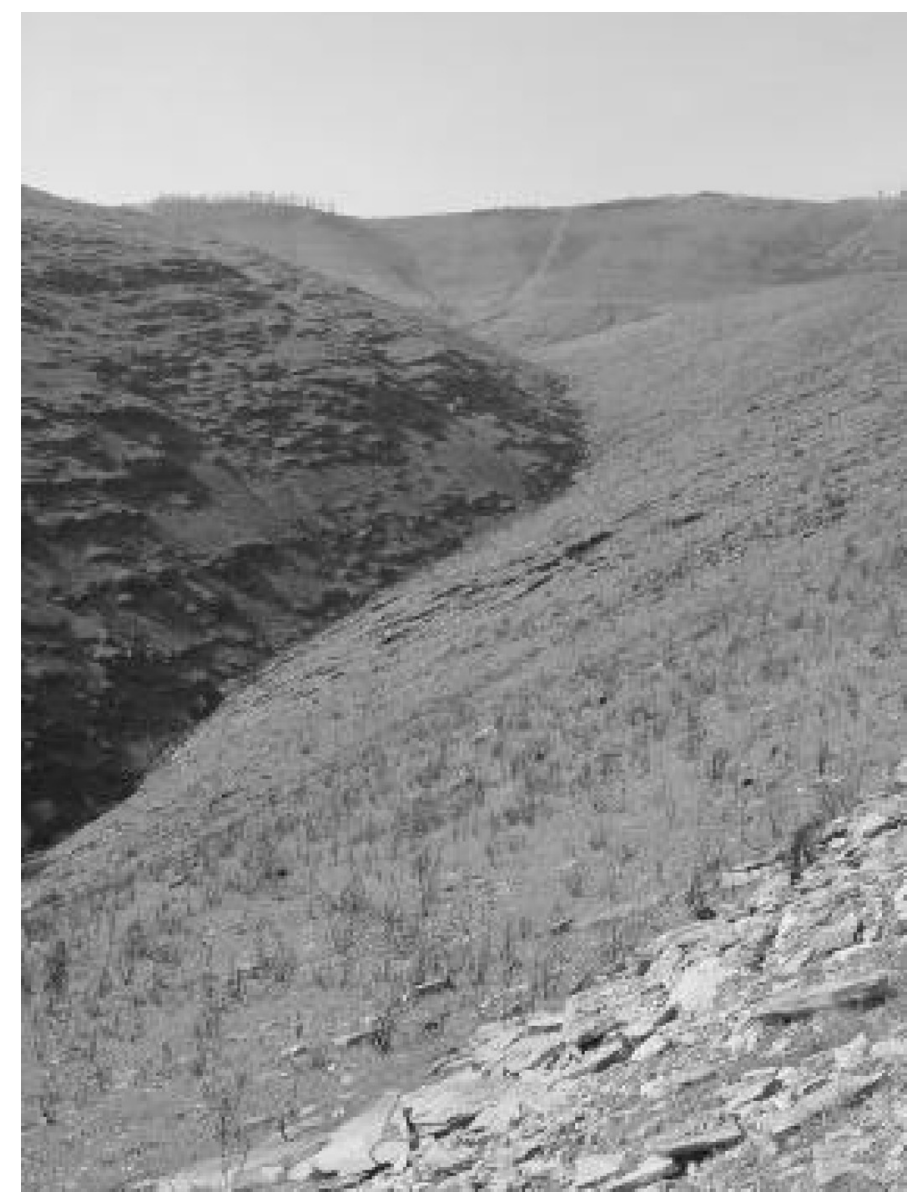

Figure 8. View from the bottom of the slope to the area where the fire was when it blew upslope until it reached the meteorological station placed at the highest point in the horizon line. 
A couple that was checking the security of their property situated at $\mathrm{D}$ quite far from the fire and in principle not endangered by it were caught by the blowup and were both killed. More details about this accident can be found in the literature (Viegas, 2004a).

At the top of the slope, at point E, there is a meteorological station that was in the way of the fire front. Due to a fire break that existed on the top of the ridge, its sensors were not destroyed-although their protections were damaged by the heat - and the recorded data were retrieved. Data were recorded every $10 \mathrm{~min}$ and the author received the data in a digital form for the period of June to September 2003. The author verified that, in spite of the heat that went across the meteorological station, its sensors continued to record normally after the fire and there is no difference between the readings before and after the event. This was not the case for the automatic precipitation meter that was virtually destroyed by the passage of the hot gases produced by the blowup.

A trace of the air temperature, relative humidity, atmospheric pressure, wind direction, and wind velocity on the August 5 is shown in Figures 9-11. As can be seen in those figures at about 18:30 $\mathrm{h}$ all the records show very abnormal behavior: the temperature (10-min averages) went up to $55.5^{\circ} \mathrm{C}$, the relative humidity dropped to $8 \%$, the average wind velocity rose to $63.8 \mathrm{~km} / \mathrm{h}$ while the maximum (in 10-min periods) reached $96 \mathrm{~km} / \mathrm{h}$.

One particularly noteworthy feature of these records is the sudden change of wind direction that occurred at 18:40 h, as shown in Figure 10b. The wind that was blowing from the northwest $\left(327^{\circ}\right)$ in a downslope direction with a velocity on the order of $12.2 \mathrm{~km} / \mathrm{h}$, turned suddenly to

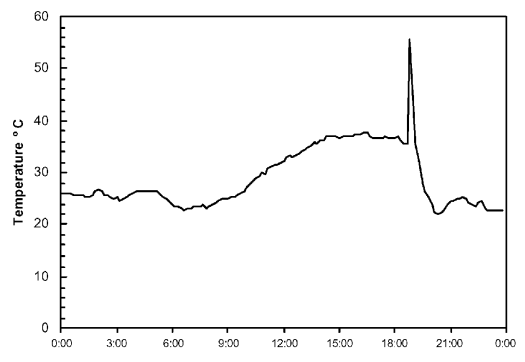

(a)

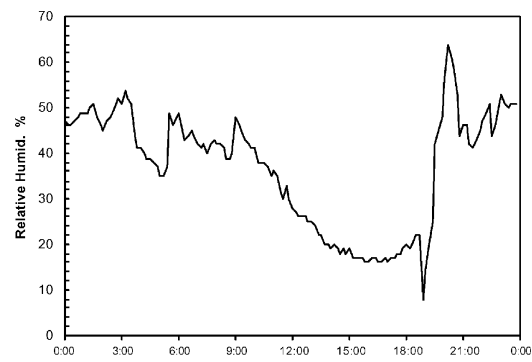

(b)

Figure 9. (a) Air temperature and (b) relative humidity at Freixo during August 5, 2003. 


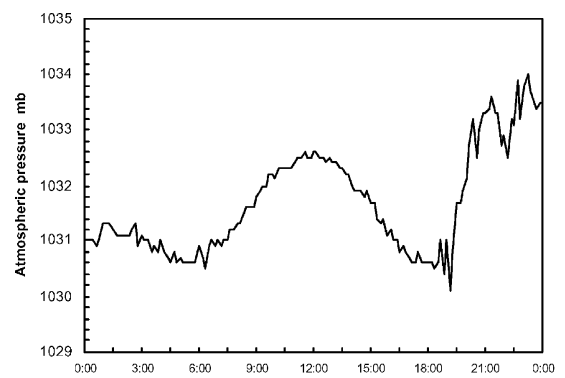

(a)

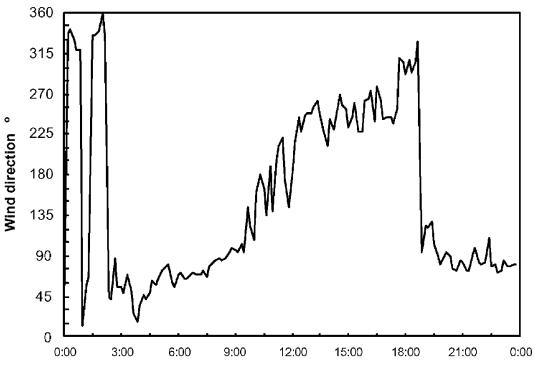

(b)

Figure 10. (a) Atmospheric pressure and (b) wind direction at Freixo during August 5, 2003.

south-southwest $\left(95\right.$ to $120^{\circ}$ ), which is approximately the direction up slope from the bottom of the river valley, and increased to about $64 \mathrm{~km} / \mathrm{h}$ 30 min later.

In the opinion of the author, this record is a clear proof that the blowup that occurred in that fire produced wind velocities on the order of $100 \mathrm{~km} / \mathrm{h}$ that cannot be explained by any other atmospheric phenomen rather than the interaction between the fire and the overall flow induced by the slope. Although there is no image record of the accident, the descriptions given by all persons interviewed by the author are consistent with a sudden fire acceleration of the fire from the bottom of the canyon to the ridge top and beyond it. The already mentioned loss of two lives is also a sad testimony of this surprising fire behavior.

The author will use this case as a further test of the model proposed here.

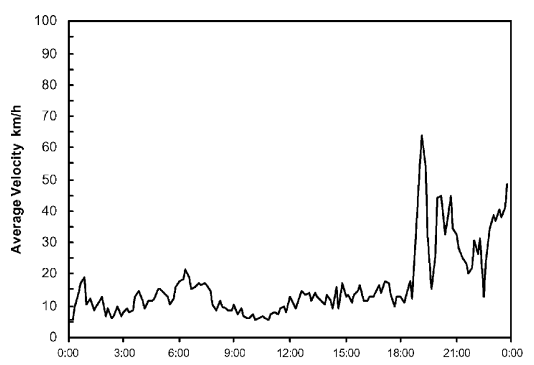

(a)

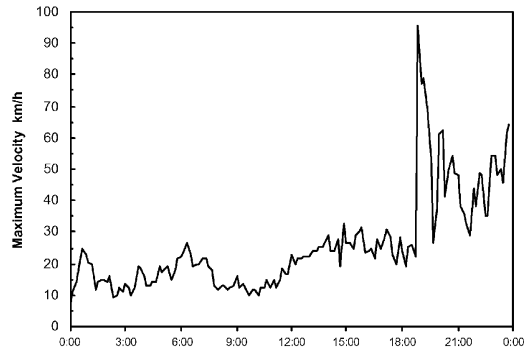

(b)

Figure 11. (a) Ten-minute average wind velocity and (b) maximum wind velocity at Freixo during August 5, 2003. 
Because we do not have a record of the fire spread that would enable us to estimate its rate of spread and to compare the corresponding results with those given by the model, we shall follow another path. We shall attempt to estimate the flow velocity induced by the fire front during its spread and compare this prediction with the registered values. This can be made easily if we compute $R^{\prime}(t)$ and then solve Eq. (13) for $U$ to obtain the distribution $U(t)$ and compare it with the observed values.

To estimate $R_{\mathrm{o}}$, we start with the determination of the average rate of spread of the fire front since its start at point $\mathrm{A}$, at $14: 30 \mathrm{~h}$, until it reached point $\mathrm{B}$, at 17:30 h. Because the distance between $\mathrm{A}$ and $\mathrm{B}$ is on the order of $1613 \mathrm{~m}$, this gives an average ROS of $R_{1}=0.15 \mathrm{~m} / \mathrm{s}$. Although the fire was spreading downslope, it was driven by favorable wind so it is reasonable to assume that its basic ROS was much less than this value. Based on the observations made in experimental fires with shrub vegetation (cf. Viegas et al., 2002c) and on the estimated values for the two previous cases, we shall consider an estimated value of $R_{\mathrm{O}}=0.01 \mathrm{~m} / \mathrm{s}$.

Because we do not have other specific data to use for this particular case, we shall adopt values of the constants in the same range that were used in the analysis of the two real cases described earlier: $a_{1}=1.1$ (SI units), $a_{2}=6 \times 10^{-5} \mathrm{~s}^{-1}, \mathrm{~b}_{2}=1.16$, and $\mathrm{t}_{\mathrm{o}}=10^{4} \mathrm{~s}$.

There is no absolute certainty about the exact moment when the blowup started. According to the testimony of the fire commander, at about 17:00 h the fire was considered controlled, and so it is reasonable to admit that it started some minutes later. Although the wind-direction change at the meteorological station occurred between 18:30 and 18:40 h, as mentioned earlier, the blowup must have initiated some minutes earlier. Its effect was felt at the meteorological station only when it dominated the prevailing weather conditions in the area. We shall assume that the origin of the blowup occurred at $17.30 \mathrm{~h}$ and we shall use the wind records starting from this time.

To integrate Eq. (17), we consider an initial value of $R^{\prime}=15$ that is the same as the value of $R_{1}^{\prime}$ computed earlier.

The results are shown in Figure $12 a$ and $12 b$. In Figure $12 a$, we can see the evolution of the ROS $R(\mathrm{~km} / \mathrm{h})$ and of the distance $x(\mathrm{~m})$ as a function of time. As can be seen after 35 to 40 min from start, the ROS increases dramatically. The estimated distance after $38 \mathrm{~min}$ is on the order of $2 \mathrm{~km}$ which is close to the real distance of $2058 \mathrm{~m}$ between points $\mathrm{B}$ and $\mathrm{E}$. 


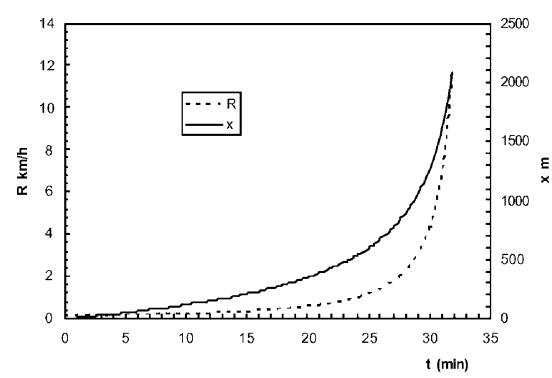

(a)

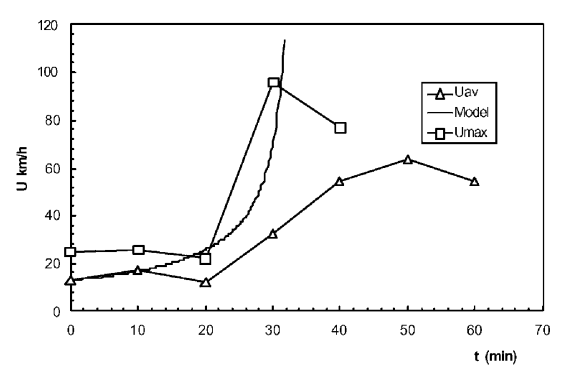

(b)

Figure 12. (a) Predicted rate of spread and distance run by the fire since the start of blowup and $(b)$ comparison between predicted flow velocity with observed values of average and maximum wind velocity.

The estimated value of the wind velocity that is required to produce the ROS at any given time was computed using Eq. (15) as said earlier. The corresponding result is shown in Figure $12 b$ and compared with the actual records for the same period of time (starting at 17:30 h). The maximum flow velocity estimated by the model for $t=32 \mathrm{~min}$ is $113 \mathrm{~km} / \mathrm{h}$, which is of the same order of the maximum wind velocity recorded at the meteorological station. The agreement between the model predictions and the observed data seems to be reasonable although it is felt that it could be improved with a better choice of the input parameters. Given the uncertainty that exists at this stage with the model and the input parameters it is felt that it is not justified to attempt such effort, as the results shown seem to be sufficient to demonstrate the soundness of the approach proposed in the present model.

\section{DISCUSSION AND CONCLUSION}

The present model describes the feedback effect between the fire-induced convection and the fire spread properties and how it affects the temporal change of fire behavior described here by the ROS of the head fire. In particular, it explains and justifies the dynamic growth of the ROS that is observed in many forest fires and shows that the blowup that occurs in steep slopes or in canyons is a natural phenomena that depends mainly on the fuel-bed properties and on the initial fire spread conditions that are dictated by terrain topography.

This model was illustrated using simplified but realistic forms obtained empirically for the functions $f$ and $g$ but these laws can also be 
derived theoretically when fire behavior theory becomes sufficiently advanced to produce them. It is believed that the results obtained and the main conclusions that were derived do not depend on the particular form of those functions. Practical application of the model requires knowledge of the following parameters: $R_{\mathrm{o}}, U_{\mathrm{o}}, t_{\mathrm{o}}, a_{1}, b_{1}, a_{2}, b_{2}$, and $R_{i}$. Each one of these parameters can be obtained independently from the present model. All these parameters are related to fuel-bed properties with the exception of $R_{\mathrm{i}}$, which depends also on terrain slope or on ambient wind. This fact puts in evidence that the blowup phenomenon is intrinsically linked to the fuel bed and to terrain or wind. The characteristic time $t_{\mathrm{o}}$ that determines time evolution or fire history is also a property of the fuel bed. From this we can conclude that, for a given fuel bed in a slope, blowup may in principle occur after a certain time. Less-steep slopes will have low initial ROS and therefore the time required for blowup to occur will be greater; therefore, if the length of the slope is not sufficiently large, blowup may not occur. On the contrary, a fire on the same fuel bed in a very steep slope will start with a high ROS and so blowup may be attained in a very short time and distance so that it is much more likely to occur.

In the model, it is postulated that functions $f$ and $g$ exist, that they are well defined, and that we can determine them. This point requires some discussion. For example, function $f$ given by Eq. (11) was obtained in this study in a combustion tunnel in which the reference velocity $U$ was the undisturbed isothermal flow velocity; it does not include the fire-induced velocity; $U_{f}$, because this was not measured. Therefore, this equation is only an approximation. In principle, it would be possible to determine function $f$ empirically by measuring the total wind velocity near the fire front and correcting the given formulation. It is believed that the corrected form of this function would not be very different from the proposed one and therefore it would lead to the same conclusion about the occurrence of blowup. Similar comments can be made about function $g$, which was not evaluated directly but was obtained using an empirical fitting to experimental data.

Perhaps even more important is the fact that functions $f$ and $g$ were obtained in a given range of conditions of fire spread and they were afterwards applied to a completely different range. For example, the maximum values of nondimensional rates of spread $R^{\prime}$ reported in laboratory or in field experiments are in the range of 20 to 100 . The present model predicts the existence of values of $R^{\prime}$ above 100 up to 1000 
or even more and apparently this is supported by field observations, as was illustrated by the three real cases presented. Again it seems that even if the forms that were used for $f$ and $g$ do not remain exactly the same outside the range of their determination, they are a good approximation and can be used to estimate, at least qualitatively, the occurrence of blowup. To the knowledge of the author, no other model predicts the sudden increase of the ROS to values as high as the present one.

The Freixo case illustrates quite well the power of the fire in a blowup and how it can entirely modify the atmospheric conditions in the close vicinity of the fire. It provided very good data on the flow velocity created by a blowup that could be used as a validation for the proposed form of the function $g$ and therefore for the entire model. Although no details on actual fire spread were obtained, there is sufficient evidence, including the loss of two lives, to consider this case as a confirmation of the present model.

The results of the present model force the author to rethink many previous case studies that he has analyzed, namely some accidents such as the one reported in the literature (Viegas et al., 2001) and some large fires that may require reinterpretation in light of the present study. It is probable that this may occur also in some works and reports published by others.

Extension of the present model to nonuniform terrain or fuel-bed properties and to non permanent boundary conditions (changing slope or wind properties) is being considered. Changes in fuel-bed properties, namely in the value of $R_{\mathrm{o}}$, will induce a modification in fire behavior: for example, the insertion of a belt of less flammable species (lower value of $R_{\mathrm{o}}$ ) will break fire acceleration and may even cut the tendency for the fire to blow up. If this tendency is proved, a method to improve the capabilities to protect the forest can be derived from the present model: the insertion of horizontal rows of less flammable vegetation to act as "blow-up breakers" in slopes.

In this model, only surface fire propagation was considered. This will certainly be the case when a single layer of fuel is involved. If trees are present, crown fires are most likely to occur with blowup, given the very high ROS values. This fire-spread regime involves other physical laws that are not considered here but it is probable that the same qualitative phenomena occur.

Butler et al. (1998) recognized that transition from slow-spreading, low-intensity fire to a fast-moving high-intensity fire occurs rapidly and that "we do not fully understand the exact mechanisms triggering these 
transitions." In the same report, the authors advance different hypotheses to explain the occurrence of blowup, most of them associated with complex wind fields or atmospheric vertical structure, which are very unlikely to occur under common conditions. A similar attitude is found in the report of other accidents, namely of Thirtymile fire. Unfortunately, this lack of knowledge associated with the proposition of very unprobable explanations leads to a general belief that blowup may occur only under those quite rare conditions. In practice, fire fighters act as if the fire would always behave calmly and they put themselves in danger more often than they should. Sometimes fire does not forgive this excess of confidence induced by the lack of knowledge and entraps fire fighters, as many past fatal accidents prove. It is quite a certainty that many more near-miss cases that did not have fatal consequences must have occurred. This only proves that sometimes even without understanding the laws of nature men can still overcome its forces and survive. It is hoped that the insight and explanation provided by this study give help to avoid repetition of such entrapments caused by lack of knowledge and by surprise.

As a final remark, the author would like to make a comment on the designation of the blowup effect. As in Latin-derived languages-like Portuguese - there is no simple translation of this term; the author proposes the use of another term borrowed from natural disaster science to designate this phenomenon. The suggested term is "fire eruption," given the similarity between a fire blowup and a volcanic eruption. The author is well aware of the physical differences between both phenomena but, in the absence of other terminology, this one is proposed.

\section{REFERENCES}

Albini, F.A. (1985) A model for fire spread in wildland fuels by radiation. Combust. Sci. Tech no1., 42, 229-258.

Brown, A.A. and Davis, K.P. (1973) Forest Fire: Control and Use, 2nd ed., McGraw-Hill, New York.

Butler, B.W., Bartlette, R.A., Bradshaw, L.S., Cohen, J.D., Andrews, P.L., Putnam, T., and Mangan, R.J. (1998) Fire behaviour associated with the 1994 South Canyon fire on Storm King Mountain, Colorado. Research Paper RMRS-RP-9, USDA, Forest Service, Rocky Mountain Research Station, September 1998.

Chandler, C., Cheney, P., Thomas, P., Trabaud, L., and Williams, D. (1983) Fire in Forestry, vols.I and II, John Wiley and Sons. 
Drysdale, D. (1992) An Introduction to Fire Dynamics, John Wiley and Sons, New York.

Furnish, J., Chockie, A., Anderson, L., Connaughton, K., Dash, D., Duran, J., Graham, B., Jackson, G., Kern, T., Lasko, R., Prange, J., Pincha-Tulley, J., and Withlock, C. (2001) Thirtymile fire investigation, Factual Report and Management Evaluation Report, USDA, Forest Service, October 2001.

Morandini, F, Santoni, P.A., Balbi, J.H., Ventura, J.M., and Lopes, J.M. (2002) A two-dimensional model for fire spread accross a fuelbed including wind combined with slope conditions. Int. J. Wildland Fire, 11, 53-65.

Nelson, R.M. (2002) An effective wind speed for models of fire spread. Int. J. Wildland Fire, 11, 153-161.

Pyne, S.J. (1984) Introduction to Wildland Fire-Fire Management in the United States, John Wiley and Sons, New York.

Pyne, S.J., Andrews, P., and Laven, R.D. (1996) Introduction to Wildland Fire, 2nd ed., John Wiley and Sons, New York.

Rothermel, R.C. (1972) A Mathematical Model for Predicting Fire Spread in Wildland Fuels. USDA, Forest Service, Research paper INT-115.

Rothermel, R.C. (1983) How to Predict the Spread and Intensity of Forest and Range Fires. USDA, Forest Service, Gen. Tech. Rep. INT-143.

Rothermel, R.C. (1993) Mann Gulch Fire: A Race That Couldn't Be Won. USDA Intermountain Research Station, Gen. Tech. Rep. INT-299.

Viegas, D.X. (2002a) The fireline rotation concept. In viegas, D.M. (Ed.) Proc. 4th Int. Conf. Forest Fire Research and Wildland Fire Safety, Millpress Science Publishers, Rotterdam, The Netherlands.

Viegas, D.X. (2004a) Cercados pelo Fogo (in Portuguese), Minerva Editora, Coimbra, Portugal.

Viegas, D.X. (2004b) On the existence of a steady-state regime for slope and wind driven fire. Int. J. Wildland Fire, 13(1), 101-117.

Viegas, D.X. and Neto, L.P. (1992) Wall shear stress as a parameter to correlate the rate of spread of a wind induced forest fire. Int. J. Wildland Fire, 2(4), 69-86.

Viegas, D.X., Silva, A.M., and Cruz, M.G. (2001) Analysis of Three Fatal Accidents Involving Portuguese Firefighters. Proc. 2001 Fire Safety Summit, Edmonton, Canada.

Viegas, D.X., Ribeiro, L.M., Matos, L., Palheiro, P., Pita, L.P., and Afonso, C. (2002b) Slope and wind effects on fire spread. In Viegas, D.X. (Ed.) Proc. 4th Int. Conf. Forest Fire Research and Wildland Fire Safety, Millpress Science Publishers, Rotterdam, The Netherlands.

Viegas, D.X., Cruz, M.G., Ribeiro, L.M., Silva, A.J., Ollero, A., Arrue, B., Dios, R., Gómez-Rodríguez, F., Merino, L., Miranda, A.I., and Santos, P. (2002c) Gestosa fire spread experiments. (In Viegas, D.X. (Ed.) Proc. 4th Int. Conf. Forest Fire Research and Wildland Fire Safety, Millpress Science Publishers, Rotterdam, The Netherlands. 